Para enlazar con este artículo / To link to this article:

http://dx.doi.org/10.14198/fem.2019.33.04

Para citar este artículo / To cite this article:

Aguado-Peláez, Delicia. «Violaciones en serie: dominaciones y resistencias tras las agresiones sexuales de ficción en la era del \#MeToo». En Feminismo/s, 33 (junio 2019): 91-116. Dosier monográfico: Diálogos entre la democracia participativa y la interseccionalidad. Construyendo marcos para la justicia social, coords. Patricia Martínez-García y Jone Martínez-Palacios, DOI: 10.14198/fem.2019.33.04

\title{
VIOLACIONES EN SERIE: DOMINACIONES Y RESISTENCIAS TRAS LAS AGRESIONES SEXUALES DE FICCIÓN EN LA ERA DEL \#METOO
}

\section{SERIAL RAPE: DOMINATION AND RESISTANCES BEHIND FICTIONAL SEXUAL ASSAULT ON \#METOO ERA}

\author{
Delicia AGUADO-PELÁEZ \\ Aradia Coop. y Universidad del País Vasco \\ deliciaaguado@gmail.com \\ https://orcid.org/0000-0001-9349-4668
}

\section{Resumen}

Esta investigación estudia la representación de la violencia sexual sobre las mujeres a través de cinco series de televisión estadounidenses que narran, al menos, una agresión sexual en el centro de la trama -Por trece Razones, Big Little Lies, Jessica Jones, El Cuento de la Criada, Westworld-. Para ello, se utiliza el análisis de contenido cualitativo desde una perspectiva interseccional y, en concreto, haciendo uso de las herramientas ofrecidas por Patricia Hill Collins. Muy brevemente, estas producciones colocan el sexismo en el centro de la matriz narrativa. Y, con ello, rehúyen una visión estereotipada de la agresión sexual y apuestan por colocar a un violador altamente normativo -blanco, clase alta, independiente...- vinculado con la víctima a través de una relación personal. Por otro lado, este perfil normativo también se presenta entre las protagonistas, invisibilizando otras relaciones de poder, sustentadas en el capacitismo o el racismo.

Palabras clave: estudios culturales, ficción, matriz de dominación, \#MeToo, violencia sexual. (CC BY 4.0)

Feminismo/s 33, junio 2019, pp. 91-116 
Violaciones en serie: dominaciones y resistencias tras las agresiones sexuales de ficción en la era del \#MeToo

\begin{abstract}
This research asses the representation of sexual violence against women through five American TV series which narrates, at least, a sexual assault in the center of the plot -13 Reasons Why, Big Little Lies, Jessica Jones, The Handmaid's Tale, Westworld-. For that purpose, qualitative content analysis is defined as a research method, using intersectionality and the matrix of domination of Patricia Hill Collins as an analytical tool. In conclusion, these productions put the sexism in the center of the narrative matrix. Therefore, they promote a non-stereotyped portrayal of sexual aggression, by introducing a highly normative rapist -white, upper class, independent...-, who has a personal connection with the victim. Conversely, the main female have are also very normative, rendering power relationships invisible, as ableism or racism.
\end{abstract}

Keywords: cultural studies, fiction, matrix of domination, \#MeToo, sexual violence.

\title{
1. INTRODUCCIÓN
}

Los medios de comunicación actúan, simultáneamente, como espejo y reflejo de nuestras sociedades. Un juego que revela lo que ocurre en nuestro entorno a la par que (re)afirma el pensamiento hegemónico. Pues, como explican Pedro Ibarra y Petxo Idoyaga, están íntimamente relacionados con los sistemas de creencias de los que hablaba Stuart Hall y, con ello, «tienen como función reproducir sistemas de dominación» (158). Con este fin en mente, necesitan presentar la ideología dominante «como legítima». Es decir, necesitan «describir esa realidad como racional, o como universal o como formando parte de una narración, de un gran relato histórico» (145). O, en otras palabras, estas estrategias de construcción simbólica (re)producen lógicas de opresión que afectan a aquellos colectivos considerados alteridad (Young) en una esfera pública que disfraza de neutralidad las relaciones de poder sustentadas en sistemas de discriminación, sea por género, raza o sexualidad, entre otros ejes y en la interacción entre ellos (Pateman, Crenshaw, Collins, Platero).

Desde este marco, el presente texto se detiene en unos productos culturales que parecen cautivar a la población mundial en las dos últimas décadas: las series de televisión producidas en los EE.UU. En este sentido, el dominio cultural estadounidense -luego de buena parte del globo- se coloca en una situación de especial interés pues actúa como un vínculo entre las instituciones sociales -estructural-, sus prácticas organizativas

Feminismo/s 33, junio 2019, pp. 91-116 
-disciplinario- y el nivel de interacción social cotidiana -interpersonal(Collins, Black Feminist 284).

Como resultado, al fijarnos en sus textos y contextos, podemos ver cómo en sus tramas se cuela buena parte de la ideología dominante del arranque de siglo. Series como 24 (Fox, 2001-2010), Battlestar Galactica (Sci-Fi, Sky One, 2003-2009) o Perdidos (Lost, ABC, 2004-2010) han reflejado a la perfección, desde las licencias que permite la ficción, las tensiones derivadas del 11 de Septiembre y de la Guerra contra el Terror de la Administración Bush. Mientras que Breaking Bad (AMC, 2008-2013) o The Walking Dead (AMC, 2015-) han hecho lo propio con las frustraciones surgidas tras la Gran Recesión que debe afrontar la Administración Obama. Tramas narradas desde la hegemonía del sujeto político normativo, ignorando -o estereotipando-cualquier personaje que se relacionara con la alteridad (Aguado-Peláez, Cuando el miedo).

Sin embargo, el campo mediático no es un espacio libre de dialéctica sino que se constituye como un inmenso ágora donde se tejen redes de poder y de producción cultural (Martín Barbero). Es decir, como un «espacio social estructurado» donde las fuerzas dominantes y dominadas están en permanente lucha entre el conservadurismo y el cambio (Bourdieu, Sobre la televisión 59). Esto es muy importante pues, pese a ser productos ligados a industrias culturales capitalistas, para comprender sus contenidos no se puede olvidar «en qué medida los sistemas de valores, las representaciones que contienen, intervienen para estimular procesos de resistencia o de aceptación del statu quo» (Mattelart y Neveu 61).

Así, y volviendo a las series, la época Obama también abre la puerta a personajes subalternos a un lado y otro de la pantalla. Hablamos de producciones como American Horror Story (Fx, 2011-), Orange is the New Black (Netflix, 2013-2019), Cómo defender a un asesino (How to get away with murder, ABC, 2014-), Transparent (Amazon, 2014-), Sense8 (Netflix, 2015-2018) o I love Dick (Amazon, 2016-2017), Y, con ellas, de Ryan Murphy, Kenji Kohan, Jill Soloway o las hermanas Wachowski. Creadoras y creadores que trasladan su propia condición de otros a las tramas desde, especialmente, los ejes género y orientación sexual -como mujeres, gays, no binarias, trans... (Aguado-Peláez Cuando el miedo; (De)construyendo reinas; Jessica Jones). 
En este sentido, estamos en un momento revolucionario de la pequeña pantalla que parece haber llegado para quedarse. Y esta implosión de series de calidad inclusivas, lejos de apagarse, parece resistir al ascenso y la llegada de Donald Trump a la Casa Blanca. Por ello, es habitual encontrar tramas que contraponen los idearios reaccionarios de la Administración. Como se puede observar con las últimas entregas de American Horror Story: Cult y Apocalypse (Fx, 2017 y 2018) o de Star Trek: Discovery (CBS, 2017-) y con creaciones como Glow (Netflix, 2017-), The Good Fight (CBS, 2017-), Las escalofriantes aventuras de Sabrina (Chilling Adventures of Sabrina, Netflix, 2018-) o Pose (HBO, 2018-), entre otras.

Esta tendencia también es reflejo de la realidad. La llegada de Trump va a coincidir con un momento álgido para los feminismos en los EE.UU. -y no solo-, como se puede ver con la Marcha de las Mujeres $(2017,2018)$ o el boom del movimiento Me Too tras el caso Weinstein que sirve para que numerosas mujeres, anónimas y famosas, denuncien situaciones vividas de acoso y agresiones sexuales.

En definitiva, y si decimos que las ficciones son espejo y reflejo, es interesante detenernos en la representación de la violencia sexual en la ficción. Unas violaciones que, en muchas ocasiones, no llegaban «al dominio de lo simbólico» (Despentes 48) y, cuando lo hacían, no acostumbraban a narrarse desde la mirada de la víctima, sino que se utilizaba como hilo conductor para tramas detectivescas o para la construcción del personaje masculino principal -arma de guerra, rape and revenge...-Sin embargo, «recientemente, estas tramas se han convertido en un elemento clave para la construcción de los personajes femeninos» (Brey 146). Argumentos que, en ocasiones, se narran como una vertiente de la violencia machista presentándola como algo estructural (Aguado-Peláez, Feminicidios con perspectiva; Jessica Jones), mientras que otras siguen haciéndolo desde los clichés (Aguado-Peláez, (De)construyendo reinas). Y, casi siempre, con amplia polémica en redes sociales.

En definitiva, las ficciones con potencial inclusivo que, aparentemente, rompen la ideología dominante a través de la presencia y voz de miembros de la sociedad catalogados como otros se antoja como un objeto de investigación de gran interés para (re)pensar nuestras sociedades. Y, más concretamente, el análisis de la representación de la violencia sexual se 
presenta como fundamental dentro de la era del Me Too. Pues nos permite preguntarnos: ¿De quiénes son las voces que narran la violencia sexual? ¿Desde qué ejes se representan? ¿Quién es el agresor? ¿Cómo es? ¿Qué relación tiene con la superviviente? ¿Cómo se bosqueja la violación? ¿Qué dominios de poder entran en juego? En suma, ¿hasta qué punto rompen con las lógicas de dominación?

\section{METODOLOGÍA}

El objetivo de la presente investigación es analizar la representación de la violencia sexual contra las mujeres de ficción a través de cinco series de televisión estadounidenses. Para ello, se parte del Análisis de Contenido Cualitativo de Big Little Lies (HBO, 2017-), El cuento de la Criada (The Handmaid's Tale, Hulu, 2017-), Jessica Jones (Netflix, 2015-), Por Trece Razones (13 Reasons Why, Netflix, 2017-) y Westworld (HBO, 2016-) -a partir de aquí, BBL, THT, JJ, 13Rw y ww, respectivamente-.

Esta metodología, como hacen referencia autores como José Luis Piñuel o José Ignacio Ruiz Olabuénaga, posibilita profundizar en el texto, tanto en su faceta manifiesta como latente y, además, aporta adaptabilidad, flexibilidad, pluriplanteamiento, proximidad y singularidad, características necesarias para la comprensión de estos mensajes. En este caso, para el estudio de la violencia sexual y del impacto que tiene en la trama a través de dos dimensiones: los personajes principales y el ambiente.

En primer lugar, el análisis de los personajes (ver TABLA 1) estudia cómo se construyen las identidades de las supervivientes principales y secundarias de la violencia sexual y de sus agresores a través de un enfoque interseccional. Esta herramienta posibilita acercarnos a estos personajes a través de diferentes ejes ${ }^{1}$, así como reflexionar sobre las relaciones de poder producidas en su encrucijada. Pues, como explica Kimberlé W. Crenshaw, las discriminaciones no son simples ni independientes. Todo lo contrario: están interconectadas, entrecruzándose y solapándose de forma dinámica, dando pie a un sistema de dominación múltiple y simultáneo

1. Los ejes de análisis en la presente investigación son los siguientes: adicciones, apariencia, clase, diversidad funcional, edad, fertilidad, género, identidad de género, etnia/ racialización, estado civil, idioma, maternidad/paternidad, naturaleza (pensada para

Feminismo/s 33, junio 2019, pp. 91-116 
Violaciones en serie: dominaciones y resistencias tras las agresiones sexuales de ficción en la era del \#MeToo

que, a su vez, crea nuevas formas de opresión. Y, con ello, permite una complejidad de análisis que sirve para comprender que «las vidas de todas, no sólo aquellas que forman parte de las minorías, están construidas sobre la base de organizadores sociales y estructurales que jerarquizan nuestras experiencias» (Platero 22).

Tabla 1: Personajes analizados

\begin{tabular}{|c|c|c|c|}
\hline SERIE & AGRESORES & VÍCTIMAS CENTRALES & VÍCTIMAS SECUNDARIAS \\
\hline 13RW & $\begin{array}{l}\text { Bryce Walker } \\
\text { (Justin Prentice) }\end{array}$ & $\begin{array}{c}\text { Hannah Baker } \\
\text { (Katherine Langford) }\end{array}$ & $\begin{array}{l}\text { Jessica Davis (Alisha } \\
\text { Boe) y Chlöe Rice } \\
\text { (Anne Winters) }\end{array}$ \\
\hline BLL & $\begin{array}{c}\text { Perry Wright } \\
\text { (Alexander Skarsgård) }\end{array}$ & $\begin{array}{c}\text { Jane Chapman } \\
\text { (Shailene Woodley) }\end{array}$ & $\begin{array}{c}\text { Celeste Wright } \\
\text { (Nicole Kidman)* }\end{array}$ \\
\hline $\mathrm{JJ}$ & $\begin{array}{c}\text { Kilgrave } \\
\text { (David Tennant) }\end{array}$ & $\begin{array}{l}\text { Jessica Jones } \\
\text { (Krysten Ritter) }\end{array}$ & $\begin{array}{l}\text { Hope Shlottman } \\
\text { (Erin Moriarty) }\end{array}$ \\
\hline THT & $\begin{array}{l}\text { Fred Waterford } \\
\text { (Joseph Fiennes) }\end{array}$ & $\begin{array}{l}\text { June Osborne } \\
\text { (Elisabeth Moss) }\end{array}$ & $\begin{array}{c}\text { Moira (Samira Wiley), } \\
\text { Emily (Alexis Bledel) } \\
\text { y Janine (Madeline } \\
\text { Brewer) }\end{array}$ \\
\hline WW & $\begin{array}{l}\text { Men in Black } \\
\text { (Ed Harris) }\end{array}$ & $\begin{array}{l}\text { Dolores Abernathy } \\
\text { (Evan Rachel Wood) }\end{array}$ & $\begin{array}{c}\text { Maeve Millay } \\
(\text { Thandie Newton)*2 }\end{array}$ \\
\hline
\end{tabular}

Elaboración propia.

Sin embargo, estos personajes y vivencias se han de leer dentro de un cosmos particular de ficción. Por ello, es necesario detenernos en el análisis del ambiente a través de la matriz de dominación de Patricia Hill

la dicotomía mutante/humanos y androides/humanos de JJ y ww, respectivamente), origen, ocupación, orientación sexual, religión, salud, sexo.

2. Tanto en el caso de Celeste Wright -sexo duro con su marido tras una fuerte discusióncomo de Maeve Millay -que provoca verbalmente a un cliente hasta que la asfixia- las escenas no están dibujadas como violaciones al uso pero sí hay una relación de abuso, poniendo de manifiesto las tensiones entre sexualidad y agresividad, entre sexualidad y poder en clave de género que coloca el foco sobre la pregunta que realiza Rita Laura Segato en su ensayo Las estructuras elementales de la violencia: « ¿cómo se puede agredir y hasta eliminar a quien un instante antes era objeto de deseo?» (44).

Feminismo/s 33, junio 2019, pp. 91-116 
Violaciones en serie: dominaciones y resistencias tras las agresiones sexuales de ficción en la era del \#MeToo

Collins (Black Feminist, The difference) que se presenta como una herramienta para reflexionar sobre la organización del poder en las sociedades de ficción. En este sentido, el análisis se centra en las diferentes opresiones y resistencias a través de los cuatro dominios de poder interrelacionados que define la autora (Collins, Black Feminist 276): a) el estructural, aquel que organiza las relaciones de poder, b) el disciplinar, que es el encargado de gestionar la opresión, c) el cultural anteriormente hegemónico, que la justifica y d) el interpersonal, que influye en la vida cotidiana y, con ello, en cómo una persona entiende su propio ser, sus experiencias y relaciones.

A partir de aquí, se pasa a exponer los principales resultados del análisis en los que se hace explícita parte del contenido de las tramas.

\section{INTERSECCIONALIDAD: LA ENCRUCIJADA DE LA NORMATIVIDAD}

\subsection{Los violadores: Más allá del cliché}

La construcción de los agresores se realiza desde la absoluta normatividad a través de diferentes ejes de dominación ${ }^{3}$. Todos ellos son hombres, blancos, anglosajones, heterosexuales, cis, sin diversidad funcional -uno de ellos con poderes-, sin adicciones y sanos. Además, se encuentran en edad productiva, pertenecientes a clases medias-altas -incluso muy altas-y ocupan posiciones de poder. Este cruce de ejes los coloca en un emplazamiento de dominio que será central en toda la trama.

Este arquetipo rehúye de ese imaginario tradicional de agresor de clase baja y/o racializado - mito del violador negro (Davis 176)- y apuesta por un perfil triunfador. En suma, estas ficciones apuntan a lo que se conoce como celebrity rape. Es decir, la tendencia en el sistema judicial estadounidense a medir la gravedad de la pena, no tanto por la agresión cometida, sino por las características del violador. $\mathrm{O}$, en otras palabras, disminuir visiblemente las penas a ciertos perfiles considerados exitosos

3. Hay algunos de estos ejes que se bordean pero siguen en la normatividad. Por ejemplo, Kilgrave (JJ) no es estadounidense pero es británico, con lo que sigue en una situación de dominio y, además, ayuda a construir el habitus del personaje con el marcado acento inglés; el MIB (WW) es sesentañero pero sigue en activo y ejerciendo una posición de poder -máximo accionista del Parque-; Walker (13RW) es estudiante pero, dentro de este eslabón, es el capitán del equipo de fútbol americano del instituto.

Feminismo/s 33, junio 2019, pp. 91-116 
Violaciones en serie: dominaciones y resistencias tras las agresiones sexuales de ficción en la era del \#MeToo

-varones blancos, de clases altas, famosos...-(Leo 153-155). Este es un aspecto importante porque, como se verá más adelante, se cuestiona la legitimidad de sus voces.

\subsection{Las supervivientes: la víctima ideal}

Las víctimas principales también se dibujan desde ejes de dominación ${ }^{4}$. Son jóvenes -entre 17 y 33 años-, blancas, cis, estadounidenses, heterosexuales y sin diversidad funcional -dos de ellas incluso con poderes sobrehumanos-. Sin embargo, hay tres grandes ejes de opresión. En primer lugar, el hecho de ser mujer. En segundo, cierta fragilidad en la salud ligada al trauma de la violación. Y, por último, ostentar un menor poder al pertenecer a clases trabajadoras y ejercer profesiones más rasas -siendo, además, habitual hacer alusión a la falta de recursos económicos-. Este perfil normativo predomina también entre las víctimas secundarias aunque podemos ver que hay una mayor heterogeneidad. Se incluyen personajes de más de 40 años -Wright (BLL) y Millay (WW)-, racializados -Davis (13RW), Moira (THT) y Millay (WW)-, lesbianas -Moira, Emily (THT)-, migrante -Millay (WW)-y de diferentes clases sociales.

El perfil de las supervivientes también se antoja fundamental porque sirve para poner el foco sobre la distinta legitimidad de voces que existen en nuestras sociedades. Dolores Juliano explica cómo se da una «correlación directa entre poder y credibilidad» pues «los sectores que tienen mayor poder monopolizan a su favor el supuesto de veracidad» (54). En este sentido, las vivencias de las víctimas mujeres -muchas de ellas trabajadoras de clases humildes- son confrontadas con las de unos agresores que se bosquejan como triunfadores a partir de la suma de ejes de privilegio. Es decir, en el mundo de ficción, al igual que en el real, las voces de las mujeres van a tener mucha menos credibilidad que la de los varones. Un aspecto especialmente delicado en el caso de las violaciones pues «la mujer violada teme decir. Sabe que contar una agresión sexual convoca imágenes equivocas. Produce evocaciones en las que los sentidos de los

4. También hay ciertos ejes al límite. Así, en la trama se hace alusión a que Baker es bisexual pero todas las relaciones sexo-afectivas de importancia que se narran son con varones. Abernathy es la anfitriona más antigua del Parque, sin embargo, su apariencia es juvenil.

Feminismo/s 33, junio 2019, pp. 91-116 
términos sexualidad, erotismo, genitalidad, violencia, transgresión y delito se deslizan unos en otros confundiéndose» (Hercovich 55).

Sin embargo, la narración de las historias de ficción va a permitir crear una paradoja. Mientras que el universo imaginario favorece a los triunfadores, la persona que está al otro lado de la pantalla está viviendo la experiencia a través de los ojos de Hanna Baker, Jane Chapman, Jessica Jones, June Osborne o Dolores Abernathy. El (sub)texto invita a la audiencia a identificarse con ellas. Como recoge Juan José Igartua la identificación se trata de un mecanismo por el cual las personas «experimentan e interpretan una narración desde dentro» (43). Una compenetración que puede jugar el rol en «los procesos de inducción afectiva» o tener impacto «en la formación o cambio de actitudes y creencias» (43). Por ello, esta conexión entre audiencia-heroína hace que sean ellas las que tengan voces legitimadas. Y, de esta forma, se logre no solo narrar los dolores de su historia sino las trabas sistémicas que la acompañan. Un hecho fundamental para (re)pensar la importancia de la credibilidad en relación con las agresiones sexuales a un lado y otro de la pantalla.

No obstante, es importante destacar que estas cinco protagonistas cumplen con el perfil de, utilizando las palabras de Juliano, una «víctima ideal» (58). Como resultado, el engranaje del mecanismo de identificación audiencia-heroína no recae sobre cualquier mujer sino que lo hace sobre una mujer dibujada desde una posición de privilegio como es el ser joven, autóctona, blanca, cis, heterosexual, con un capital cultural medio o alto y sin discapacidades.

Una sobrerrepresentación que invisibiliza las realidades de las otras, grupos alteros usualmente olvidados y que se encuentran en posiciones mucho más vulnerables. Es decir, se silencian las vivencias de mujeres de clases muy bajas; con cuerpos no normativos; con algún tipo de discapacidad; de edad muy joven o avanzada; estigmatizadas -adictas, prostitutas o sin hogar-; lesbianas; migrantes; racializadas, y/o trans, entre otras. Muchos de esos colectivos son, además, víctimas usuales de las violaciones que, sin embargo, en estas narraciones quedan fuera del juego de la visibilidad, de la identificación con el público y, con ello, de la credibilidad.

Como se ha apuntado, esta normatividad se debilita levemente entre los personajes secundarios de tres de las series analizadas: 13RW, THT 
Violaciones en serie: dominaciones y resistencias tras las agresiones sexuales de ficción en la era del \#MeToo

y $\mathrm{WW}^{5}$. Algo que permite introducir la mirada de mujeres lesbianas, migrantes, racializadas y/o prostitutas en torno las agresiones sexuales. Sin embargo, el hecho de aparecer como narraciones secundarias tiende a tener un efecto perverso en el que, más que ser un altavoz para voces alternas, termina al servicio de la construcción del personaje principal o, incluso, cayendo en arquetipos fuertemente estereotipados.

Así, la primera temporada 13RW introduce la violación de Jessica Davis, una joven racializada y amiga de la protagonista. Sin embargo, su vivencia va a estar narrada a través de Baker -que, aunque sin decir su nombre, relata la agresión en las cintas que graba antes de suicidarse- y su aliado Clay Jensen (Dylan Minnette), que intentará convencer a Davis para que denuncie. De esta forma, gran parte del peso de la narración -y, con ello, de la credibilidad- de la experiencia se desplaza de la superviviente a Baker y Jensen -ambos no racializados-.

En segundo lugar, nos encontramos con THT donde las mujeres son privadas de todo derecho y consideradas mercancías ${ }^{6}$. En este contexto, realizan pequeños actos de resistencia como enamorarse, revelar sus verdaderos nombres, escribir sus biografías de forma subversiva o intentar escapar ayudadas por la resistencia en el conocido como tren de las mujeres -female road-. En definitiva, todos estos actos recuerdan a las vivencias de las personas negras estadounidenses durante la esclavitud que fueron recopiladas, entre otras, por Angela Davis en Mujeres, raza y clase. Es decir, esta distopía futurista tiene fuertes ecos del pasado de la comunidad negra estadounidense y, sin embargo, la historia es narrada a través de una protagonista blanca. Si bien es cierto que la serie se distancia de la novela y realiza un esfuerzo por corregir este desacierto apostando por personas afroamericanas para representar a su marido -Luke Bankole (O-T

5. También en BLL entra el eje edad pues Wright está interpretado por Nicole Kidman (1967). Sin embargo, aunque en la TABLA 1 se haya clasificado como personaje secundario, lo es solo en cuanto a la construcción narrativa en clave a la violación. Por lo demás, ocupa un papel de coprotagonista por lo que no se desarrolla en la misma línea que el resto de mujeres señaladas aquí.

6. Son alejadas de sus maridos e hijos pre-Gilead; obligadas a ejercer todo tipo de trabajos -durísimos en las Colonias-; no se les permite leer ni escribir; son forzadas a concebir y separadas de sus criaturas; maltratadas y torturadas como disciplina; violadas por los hombres sujetos de derechos -dentro y fuera de la ceremonia-, etc.

Feminismo/s 33, junio 2019, pp. 91-116 
Violaciones en serie: dominaciones y resistencias tras las agresiones sexuales de ficción en la era del \#MeToo

Fagbenle)-y su hija -Hannah Bankole (Jordana Blake) - ${ }^{7}$, algo que permite realizar ciertos guiños a la comunidad afrodescendiente, sigue teniendo ciertas carencias en cuanto a la profundidad y la legitimidad de sus voces.

A este respecto, es interesante detenernos en el caso de Moira, una joven afroamericana, lesbiana activista feminista que es la mejor amiga de la protagonista. Con la llegada de Gilead, es catalogada como criada pero termina degradada por intentar escapar del Centro Rojo. Tachada como influencia corrupta le dan a elegir entre las Colonias -campos de concentración híper contaminados- o Jezabel ${ }^{8}$ - un prostíbulo secreto para la élite-. Ante la alternativa, elige el segundo: «It's a few good years before your pussy wears out. All the booze and drugs you want. Food's good. We only work nights. I mean, it's not so bad» (108 Jezabels). Tras una temporada como prostituta -llamada Ruby-, logra fugarse a Canadá, donde se reencuentra con Luke, el marido de la protagonista.

Durante este periodo, Moira pasa a convertirse en Ruby para ser puesta, noche tras noche, a disposición de poderosos hombres (mayoritariamente) blancos. Esta experiencia más cercana a la trata que a la prostitución se da en la encrucijada entre ideología y cuerpo donde cruza su compromiso por los derechos de las mujeres, lo queer y lo racializado. Sin embargo, esta vivencia queda desdibujada en la trama al ser básicamente narrada desde los ojos de Osborne. De hecho, en la segunda temporada, las referencias al trauma quedan relegadas a breve pinceladas en la trama-como practicar sexo esporádico bajo un rol activo en un bar con una desconocida tras el pseudónimo de Ruby- y al episodio Smart Power (209) donde se encuentra con el Comandante Waterford.

7. En una entrevista en Time a Bruce Miller, director de la serie, explica como el tema racial fue una de las diferencias con Margaret Atwood pues su novela no contiene ningún personaje racializado: «What's the difference between making a TV show about racists and making a racist TV show where you don't hire any actors of color? So that was part of it.» Más info: <http://time.com/4754200/the-handmaids-tale-showrunner-changes-from-book/>

8. La vinculación directa de Moira con Jezabel vuelve a tener un gran peso simbólico pues su figura se ha relacionado históricamente con las afroamericanas para ejemplificar la «imagen de la mujer negra de moral distraída» algo que «se empezó a transmitir a través de la imagen de la mujer esclava [...] como una figura exótica, una mujer lasciva cuya sensualidad desatada estaría ligada a su gran fecundidad» (Brey, 138).

Feminismo/s 33, junio 2019, pp. 91-116 
Brevemente, el Comandante y su esposa, la poderosa familia a la que Osborne es adjudicada, hacen una visita a Canadá para vender las bondades de la República de Gilead -incluyendo la voluntariedad de las mujeres implicadas-. La trama narra el sufrimiento de las personas refugiadas por este movimiento diplomático - «he's a fucking war criminal [...] he's a serial rapist!»- y los eminentes acuerdos derivados. Sin embargo, Luke logra hacerse con un paquete de cartas escritas por las propias criadas narrando sus vivencias - de nuevo, un eco de la esclavitud ${ }^{9}$ - que despertará el rechazo de la opinión pública. El gobierno canadiense invitará a irse a los Waterford bajo la frase «we believe the women».

En este contexto, llama la atención que en la narración no haga ninguna alusión a la necesidad de poner el foco mediático sobre las experiencias de Luke y Moira. No solo por su condición de refugiados que conocen de primera mano los horrores de Gilead, sino porque Luke es el marido de la mujer que tiene de criada el Comandante y Moira fue puesta a su disposición en Jezabel. En este momento, la trama ni siquiera problematiza que los dos personajes afroamericanos no tengan ningún tipo de voz pública. Todo pasa desapercibido dejando la voz de Moira relegada a un cartel con su nombre ante el comandante «Not Ruby, asshole». El gobierno canadiense cree a las mujeres, pero no a Moira.

En consecuencia, la normatividad de la víctima principal se utiliza como recurso de caballo de Troya para conectar y empatizar con el público. De esta forma, las voces subalternas -cuando las hay- se dejan en un segundo plano como complemento a las mismas. Cumpliendo con la teoría de Juliano, la falta de credibilidad se ensaña con las mujeres y, especialmente, con «sus sectores con menos prestigio» (54).

Por último, es necesario hacer mención al cruce del eje racialización y prostitución que afecta a dos de las supervivientes secundarias afrodescendientes, la citada Moira y Maeve Millay (ww). En la otra serie distópica futurista con raíces en el pasado, esta vez en el antiguo Oeste, Millay se presenta como la madame de Mariposa, el burdel de Westworld. En ella

9. Como explica Angela Davis: «el fenómeno tan extendido de la narración autobiográfica de los esclavos fue la principal herramienta de propaganda política utilizada por el movimiento abolicionista en el periodo anterior a la guerra civil, además de su importancia posterior en la tradición literaria afroamericana» (27). 
pesan los ejes mujer, negra, migrante y madame. Una profesión que le da cierto poder en el tablero de juego al usar su sexualidad como recurso para manipular a los hombres, como se puede ver en esta alegórica frase: «At first, I thought you and the others were gods. Then I realized you're just men. And I know men» (107 Trompe L'Oeil). Así, parte de sus aliados tendrán como vínculo la atracción sexual hacia ella, como es el caso de Hector Escaton (Rodrigo Santoro) y Felix Lutz (Leonardo Nam).

En este sentido, cabe destacar una escena. Millay intenta descubrir la verdad tras sus extraños sueños y decide provocar su propia muerte. Para ello, se burla de la virilidad sexual de un cliente -«[...] the time I got down to my knickers, I suspect you'd be done anyway. [...] Such a big man. So big all over, except where it counts. Darling, when I gave you a turn on the house, I thought you might give me something in return, anything»-, mientras coloca sus manos alrededor de su cuello invitándolo a que la estrangule - «That's it, don't be shy»- (106 The Adversary). Esta escena hace de Millay el caso más diferente entre todas las compañeras analizadas ya que la construcción de la escena no está presentada como una violación aunque la violencia sexual y de género es explícita.

De esta forma, aunque ambos personajes se dibujan de manera compleja y con fuerte iniciativa en la trama, se aproximan, en cierto modo, al estereotipo de mujer negra arrastrado desde la esclavitud pues, como explica Davis, «La imagen ficticia del hombre negro como violador siempre ha reforzado a su inseparable pareja: la imagen de la mujer negra como depositaria de una promiscuidad crónica» (183). Es decir, las dos son ligadas con prostíbulos -Jezabel y Mariposa-y, pese a que en ambos casos podamos ver más paralelismo a la trata que a la prostitución -una por su condición de androide diseñada y manipulada por humanos y otra como alternativa a un campo de concentración-, las dos mujeres afroamericanas se vinculan a la prostitución y al uso consciente de su sexualidad como resistencia. En consecuencia, se va a restar peso a su voz como víctimas en la trama. «Vistas como «mujeres perdidas» y como putas, los gritos de violación proferidos por las mujeres negras carecerían, inevitablemente, de legitimidad» (Davis 184). 
Violaciones en serie: dominaciones y resistencias tras las agresiones sexuales de ficción en la era del \#MeToo

\section{MATRIZ DE DOMINACIÓN: DESMONTANDO AL MONSTRUO}

\subsection{Estructural: Entre el consentimiento y la coerción}

Los diferentes géneros en los que hibridan los dramas analizados dejan escenarios totalmente diversos (ver TABLA 2) lo que nos permite explorar cómo las ficciones imaginan diferentes ámbitos estructurales. Así, 13RW, BLL y JJ, con gran apego a la realidad, representan la democracia representativa capitalista estadounidense, aunque con matices -por ejemplo, el peso neo(noir) de JJ enfatiza la decadencia institucional desde esa oscuridad y pesimismo tan propios-. En general, los EE.UU. se bosquejan como lo que Alicia Puleo denomina patriarcado de consentimiento. Es decir, un sistema de opresión sutil basado en mecanismos de dominación simbólica como los señalados por el sociólogo Pierre Bourdieu en La dominación masculina.

Tabla 2: Dominio Estructural

\begin{tabular}{|c|c|c|c|c|c|}
\hline SERIES & $13 \mathrm{RW}$ & BLL & $\mathrm{JJ}$ & THT & Ww \\
\hline \multirow[b]{2}{*}{$\begin{array}{l}\text { ESCENARIO: } \\
\text { EE.UU. }\end{array}$} & \multirow{2}{*}{$\begin{array}{l}\text { Instituto } \\
\text { de una } \\
\text { pequeña } \\
\text { ciudad }\end{array}$} & \multirow{2}{*}{$\begin{array}{l}\text { Monterrey, } \\
\text { pueblo costero } \\
\text { californiano }\end{array}$} & \multirow{2}{*}{$\begin{array}{l}\text { Hell's } \\
\text { Kitchen } \\
\text { (Nueva } \\
\text { York) }\end{array}$} & \multirow[b]{2}{*}{$\begin{array}{l}\text { República de } \\
\text { Gilead }\end{array}$} & EE.UU. \\
\hline & & & & & Parque \\
\hline GÉNERO & Cotidiano & Cotidiano & $(\mathrm{Neo})$ noir & Distópico & Western \\
\hline \multirow[b]{2}{*}{$\begin{array}{c}\text { SisTEMA } \\
\text { POLÍTICO }\end{array}$} & \multirow[b]{2}{*}{ Democracia } & \multirow[b]{2}{*}{ Democracia } & \multirow[b]{2}{*}{ Democracia } & \multirow[b]{2}{*}{ Teocracia } & Democracia \\
\hline & & & & & $\begin{array}{c}\text { Salvaje Oeste } \\
\text { mitificado }\end{array}$ \\
\hline \multirow[b]{2}{*}{$\begin{array}{c}\text { SISTEMA } \\
\text { ECONÓMICO }\end{array}$} & \multirow[b]{2}{*}{ Capitalismo } & \multirow[b]{2}{*}{ Capitalismo } & \multirow[b]{2}{*}{ Capitalismo } & \multirow[b]{2}{*}{ Autarquía } & Capitalismo \\
\hline & & & & & $\begin{array}{c}\text { Anarco- } \\
\text { capitalismo }\end{array}$ \\
\hline $\begin{array}{l}\text { SISTEMAS DE } \\
\text { DOMINACIÓN }\end{array}$ & $\begin{array}{l}\text { Clasismo, } \\
\text { homofobia } \\
\text { y sexismo }\end{array}$ & $\begin{array}{l}\text { Clasismo y } \\
\text { sexismo }\end{array}$ & $\begin{array}{l}\text { Clasismo y } \\
\text { sexismo }\end{array}$ & $\begin{array}{c}\text { Clasismo, } \\
\text { homofobia y } \\
\text { sexismo }\end{array}$ & $\begin{array}{l}\text { Capacitismo, } \\
\text { clasismo, } \\
\text { colonialismo, } \\
\text { especismo, } \\
\text { racismo y } \\
\text { sexismo }\end{array}$ \\
\hline EFECTOS & & $\begin{array}{c}\text { Competitividad, } \\
\text { individualismo, } \\
\text { insatisfacción, } \\
\text { moralismo }\end{array}$ & & & $\begin{array}{c}\text { Asesinatos y } \\
\text { violaciones } \\
\text { como } \\
\text { diversión } \\
\end{array}$ \\
\hline SILENCIOS & Racismo & Racismo & Racismo & Racismo & \\
\hline
\end{tabular}

Elaboración propia. 
De esta forma, estas series bosquejan una democracia incompleta y un sistema económico que enfatiza lógicas clasistas, machistas y heteronormativas -mientras olvidan problematizar otras como el capacitismo o el racismo-. Este marco tiene un impacto en la representación de la violación pues está perseguida y penada formalmente pero las víctimas se van a encontrar las zancadillas de estos sistemas de dominación.

Por otro lado, las dos ficciones distópicas apuestan por una teocracia autárquica con la República de Gilead (THT) y por el anarco-capitalismo a través de una recreación idealizada del Antiguo Oeste en el Parque de Westworld (ww). Dos sistemas más ligados con lo que Alicia Puleo denomina patriarcado de coerción donde los roles de género están fuertemente marcados y transgredirlos puede acarrear duros castigos, incluso la muerte. Algo que se acompaña con otras lógicas de dominación como capacitismo, clasismo u homofobia... En este contexto, las violaciones son algo inherente a estos sistemas y, con ello, protegen al agresor mientras desamparan a la víctima. En el primer caso, se encuentran bien institucionalizadas a través del rito de la ceremonia, bien invisibilizadas por la ausencia de legitimidad de voces de las mujeres, aunque se castigan con lapidación aquellas que sí son catalogadas como tales. En el segundo caso, son una actividad lúdica más.

\subsection{Disciplinar: Entre la falsa igualdad formal y el panóptico}

Como los ámbitos están fuertemente interconectados, la concepción del dominio estructural afectará de lleno al dominio disciplinar. En el caso de 13RW, BLL y JJ, la matriz de dominación se expresa cuando personajes ligados con la justicia, la policía o el profesorado aplican un protocolo que invisibiliza los efectos del sexismo y otras lógicas de dominación en base a la igualdad formal, la eficiencia o la racionalidad. Algo que lleva a poner en duda la credibilidad de las víctimas de tal forma que estas prefieren guardar silencio y, cuando lo rompen, no solo no reciben amparo institucional sino que terminan viviendo una doble-victimización.

Esto puede verse cuando, en 13RW, el orientador insinúa que exagera y la invita a pasar página, el entrenador y su entorno protege a su jugador y los jueces parecen centrarse más en la moralidad de la víctima -consumo de drogas, bullying previo, relaciones sexo-afectivas...-que en la agresión.

Feminismo/s 33, junio 2019, pp. 91-116 
En BBL es la propia comunidad la que ejerce como cárcel bajo el mandato de la mujer como superwoman que no permite ninguna desviación. Así como en JJ, Jones se volcará en demostrar la culpabilidad de Kilgrave como única forma de probar la inocencia de Shlottman. Un camino en el que encontrará aliados -entre ellos, dos policías- pero siempre a título individual y nunca como respaldo institucional.

Por otro lado, entre las segundas se puede apreciar un fuerte entramado burocrático encargado de vigilar y castigar. En el caso de THT, hablamos de grupos como los Hijos de Jacob -Sons of Jacob y sus milicias armadas The Guardians of the Faithful-, Los Ojos -The Eyes-, el Centro Rojo-Red Center-, las Colonias-Colonies-... que racionalizan su poder en base a la persecución de una sociedad pecadora culpable de las catástrofes medioambientales y de la falta de natalidad. Algo que justifica su capacidad para imponer castigos psicológicos y físicos -entre los que se cuentan amputaciones y ejecuciones públicas-. Por su parte, en wW la vigilancia se escenifica en un Parque pensado como el panóptico de Foucault en el que las narraciones asignadas a los androides funcionan como un acto de rutinización eterno -repetido en bucle entre borrado y borrado-. Todo ello justificado por la ley del más fuerte derivada del sistema capitalista y que funciona tanto para los accionistas como para los visitantes. En estos marcos, las violaciones se justifican como algo natural y quedan amparadas bajo el orden supremo.

\subsection{Cultural: entre el sujeto y el objeto}

En este dominio, las violaciones se dibujan en el seno de comunidades que permiten y fomentan esta construcción. En todas las ficciones analizadas, el control del comportamiento se realiza desde la propia comunidad, que observa y juzga desde el prejuicio cualquier comportamiento que se sale de la norma, invisibilizando y justificando las violaciones y el maltrato -en diferentes niveles según la serie: asesinatos, bullying, violencia machista, torturas, etc.-.

Además, las cinco ficciones se vuelcan en relacionar la problemática entre masculinidad tóxica -y el binarismo de género- y el consentimiento en un contexto que descansa sobre la cultura de la violación. Lo primero que hay que destacar es que los agresores cumplen con el modelo 
hegemónico de masculinidad. «Relacionada con la voluntad de dominio y control, es un Corpus construido socio-históricamente, de producción ideológica, resultante de los procesos de organización social de las relaciones mujer/hombre a partir de la cultura de la dominación y la jerarquización masculina» (Bonino 9).

Más aún, Bourdieu en La dominación masculina explica cómo la oposición entre lo masculino y femenino «recibe su necesidad objetiva y subjetiva de su inserción en un sistema de oposiciones homólogas». Oposiciones mítico-rituales de pares arriba/abajo, seco/húmedo, cálido/ frío, activo/pasivo que nuestras sociedades vinculan con masculino/femenino y, con ello, «la posición considerada normal es lógicamente aquella en la cual el hombre «toma la iniciativa», «está arriba»». (31). «Encima o debajo, activo o pasivo, estas alternativas paralelas describen el acto sexual como una relación de dominación [...] Las manifestaciones (legítimas o ilegítimas) de la virilidad se sitúan en la lógica de la proeza, de la hazaña, que glorifica, que enaltece» (33).

En el caso de las ficciones, introducen claramente otro par: la condición de sujeto/objeto. En este sentido, para poder poseer libremente un cuerpo, es necesario que el violador (de)construya la humanidad de la víctima y la convierta, en cierta forma, en un objeto. El caso más claro viene de la mano de 13RW cuya trama avanza a medida que Baker pierde su condición de sujeto en objeto de deseo -el mejor culo, la que hace tríos, la fácil-. La protagonista aprende lo que xTx en su ensayo dentro de No es para tanto (Gay 123) denomina «marcador» que va aumentando cuando se viven experiencias derivadas de esta condición de objeto: «Cuando te enseñan a ser niña, sencillamente asimilas las lecciones: es el precio que pagas por tener curvas, por tener orificios».

No es la única, por su parte, BBL dibuja a un Wright altamente posesivo «Look at her, she can have any men she wants [..,] that terrifies me. From the very beginning like when we first met. I've always worried that she would just go through me» (103 Living the dream). En JJ, Kilgrave trata a sus víctimas como muñecas -las viste a su gusto, ordena que salten durante horas para su deleite...-. Por otro lado, THT narra una sociedad en la que las mujeres son despojadas de todo derecho hasta ser convertidas en recipientes. Y, WW parte de que las víctimas son, directamente, cosas, 
ginoides: «Who the fuck cares what Dolores wants? She's a goddamn doll» (105 Contrapasso), espetará Logan Delos (Ben Barnes).

En este sentido, Rodrigo Parrini, en un estudio sobre la alteridad en la violencia sexual a través del testimonio de violadores, destaca cómo el discurso de los agresores se construye a través del citado binarismo de género, agarrándose a que mientras «la sexualidad pertenece a los hombres, el sexo a las mujeres» (134). Una idea que sigue la dicotomía entre «el 'impulso sexual' masculino como motor de la violación y el sex appeal femenino como lo que lo encendería» (Hercovich 102).

Así, en las ficciones analizadas, todos los agresores son conscientes de sus actos y, de hecho, la mayoría son reincidentes -con más de una violación bien a la misma víctima, bien a diferentes mujeres-. Sin embargo, se apoyan en la ideología dominante para reasignar un significado al significante. Porque ellos no violan, tan solo muerden la manzana. La legitimación y la culpa en una misma moneda que se resume a la perfección en las palabras de Walker en 13RW: «She wanted me. Me. She was practically begging me to fuck her. If that's rape then every girl at this school wants to be raped» (112, Tape 6, Side B). En este caso, encontramos un contrasentido. A ojos de los violadores, y de parte de la sociedad, se produce una inversión de roles donde las mujeres pasan de objetos pasivos de deseo a sujetos activos culpables. Es decir, «invertir significados y convertir víctimas en victimarios» (Hercovich 63)

De esta forma, al construir al agresor desde la masculinidad hegemónica permite problematizar esta posición de dominio fruto de la complicidad del ámbito estructural, disciplinar y cultural -y que crece y se fortalece, aún más, con cada uno de los ejes de privilegio con los que se construye-. Y, con ello, visibilizar la idea de Virginie Despentes:

La violación es lo propio del hombre; ni la guerra, ni la caza, ni el deseo crudo, ni la violencia o la barbarie, la violación es lo único que las mujeres -hasta ahora- no se han reapropiado. La mística masculina debe construirse como si fuera peligrosa, criminal e incontrolable por naturaleza. Por ello debe ser rigurosamente vigilada por la ley, gobernada por el grupo. [...] La violación, el acto condenado del que no se debe hablar, sintetiza un conjunto de creencias fundamentales sobre la virilidad (59-60). 
Violaciones en serie: dominaciones y resistencias tras las agresiones sexuales de ficción en la era del \#MeToo

Una masculinidad tóxica que, en muchos casos, se apoya en una fraternidad cerrada que legitima sus actos - muy visible en 13RW, THT y wW-. Sin embargo, como hemos dicho, las narraciones están contadas a través de los ojos de las supervivientes y, con ello, permite desmontar esta dicotomía. Esto se realiza huyendo del placer visual desenmascarado por Laura Mulvey en la recreación de las violaciones -o incluso eludiendo la escena como en el caso de JJ-. A este respecto, otro diálogo fuertemente alegórico viene de la mano de Kilgrave y Jones (108 WWJD?):

- Which part of staying in five-star hotels, eating in all the best places, doing whatever the hell you wanted, is rape?

- The part where I didn't want to do any of it! Not only did you physically rape me but you violated every cell in my body and every thought in my goddamn head.

Esta frase nos introduce de lleno en la idea de consentimiento. Estas producciones enfatizan ese no es no y se centran en desmontar que no existe agresión si no hay una oposición física. Todas las víctimas de las ficciones quedan paralizadas. Así, siguen la idea plasmada por Jana Leo en su ensayo Violación Nueva York en el que vuelve a definir este acto como «una forma de dominar y de marcar un espacio». Pues el violador «se adueña del universo personal de la persona violada; la violación es una forma de domesticación, con ella se marca el territorio, se ejerce control sobre la persona y se actúa mediante una amenaza (esta vez es violación, la siguiente será muerte)» (148). A este respecto, es muy significativa la narración de la experiencia de Chapman (103 Living the Dream):

We met in a bar. He was funny and sexy, and we were both pleasantly drunk. We got a hotel room that overlooked the ocean. It was beautiful and romantic. Ahem, and then he changed [...] He became extremely aggressive. It was like he was operating some piece of machinery or something. It was just so rote. I tried to resist, but he was way bigger than I was. I eventually just stopped resisting because I was actually afraid that he would kill me. He finished got up, and, um said goodbye. And I said bye. That was it.

\subsection{Interpersonal: entre lo individual y lo sororo}

La experiencia de Chapman nos introduce en el último de los dominios: el interpersonal. Las producciones se alejan de la visión arquetípica de la 
violación que se da en un callejón oscuro por un desconocido y se apuesta por representar la versión más extendida. Según las estadísticas de Rape, Abuse and Incest National Network, «cuatro de cada cinco agresiones son agresiones cometidas por personas cercanas a la víctima y en un $47 \%$ de los casos, el violador es un amigo o un conocido de la misma» (Brey 146). En el caso de 13RW y de BLL, además, se hace alusión al date rape (Leo 156, Gay 16-19), una cita que termina en violación y que hoy es motivo de protestas por estar fuertemente extendida en la vida universitaria estadounidense.

En las narraciones, esta relación complica la identificación de la agresión y, entre culpabilidad y desconcierto, hace que muchas de ellas opten por no denunciar, a sabiendas del desamparo que les espera. Un vínculo que dificulta la superación del trauma. Main Street, Birch Street, Higgins Drive, Cobalt Lane: La lista de las calles en las que ha vivido Jones es el mantra que repetirá una y otra vez cada vez que el recuerdo púrpura de su agresor viene a su mente. Pues, entre las supervivientes, estará muy presente el estrés postraumático -Chapman (BLL)- que las arrastra a adicciones -Davis (13RW), Jones (J) - o a continuos saltos en la consciencia -Abernathy (WW)-. Incluso a pensamientos suicidas -Chapman (BLL) - o al (intento de) suicido -Baker (13RW), Shlottman (J) o Janine (THT)-.

Ante este escenario, las producciones colocan las relaciones humanas como centrales para superar el trauma y enfrentarse al agresor. Y, dentro de estas, cobran especial fuerza las relaciones sexo-afectivas heterosexuales -Baker, Osborne, Dolores y, en cierta forma, Jones- y, especialmente, la sororidad. La amistad entre mujeres es el camino de Chapman, Jones y Osborne que, a través de pequeñas acciones, van tomando consciencia de su opresión y actuando en consecuencia, dentro de las limitaciones estructurales, disciplinarias y culturales. Esto no quiere decir que se apueste por una confrontación masculino/femenino a través de una visión esencialista y reduccionista de la mujer dibujada desde la bondad pura. Todo lo contrario, todas ellas tienen mujeres en el centro de la trama que ejercen el papel de antagonistas y/o villanas. 
Violaciones en serie: dominaciones y resistencias tras las agresiones sexuales de ficción en la era del \#MeToo

\subsection{Resistencias: entre el heroísmo cotidiano y el extraordinario}

«Nolite te bastardes carborundorum, bitches» ${ }^{10}$. La frase que se ha convertido en un emblema de THT es toda una declaración de resistencia. Así, esta idea de domesticar para hacer de las mujeres objetos pasivos se va desmontando a medida que se identifica la dominación. Como alegóricamente explica Osborne (108 Jezebels) cuando le regalan una cajita de música:

A perfect gift. A girl trapped in a box. She only dances when someone opens the lid, when someone else winds her up. If this is a story I'm telling, I must be telling it to someone. There's always someone, even when there's no one. I will not be that girl in the box.

Todas las series dibujan resistencias aunque se hace de forma muy diferente. Por un lado, BLL y JJ tan solo encuentran apoyo en el ámbito interpersonal, abandonadas por el resto de dominios, terminan encarándose con un agresor que acaba asesinado. Sin embargo, las relaciones entre las mujeres de este dominio son tan fuertes que incluso consiguen solventar las diferencias entre ellas por una protección común -BLL- o introducir en las tramas con naturalidad temas muy complejos como el aborto -JJ-.

Por otro, 13RW parte de un suicidio que llega cuando los cuatro dominios fallan a la víctima y ella se ve tan sola que no puede continuar. Sin embargo, sus cintas sí que servirán para sacudir el dominio interpersonal -y hacer que Davis y Rice identifiquen sus opresiones- y visibilizar las trabas del ámbito sistémico estructural y disciplinario. A este respecto, cabe destacar cómo quitarse la vida se presenta como salida a una situación emocional insostenible pero también como un acto de sacrificio para un bien común. Pues el suicidio de Baker va a servir para darle fuerza a su historia, el de Shlottman para liberar a Jones de su contención y hacer que asesine a Kilgrave y el de Janine para que su hija no creciera en ese ambiente opresor.

Por último, THT y WW muestra pequeñas resistencias que avanzan hacia la revolución. «It's their fault. They should have never given us uniforms if they didn't want us to be an army» (110 Night), espetará Osborne. Algo que se justifica en la necesidad imperiosa de modificar el

10. «Don't let the bastards grind you down» «No dejes que los cabrones te hagan polvo» (104 Nolite Te Bastardes Carborundorum).

Feminismo/s 33, junio 2019, pp. 91-116 
dominio sistémico -y con él, el disciplinar y cultural- que, es tan inamovible, que necesita un gran golpe de efecto. Así, en ww, se presenta como una revuelta de los robots encabezados por una Abernathy -que abraza su parte masculina al asimilar parte de la personalidad de un forajido- y que opta por una justicia abstracta a través de la revolución violenta.

En general, esta necesidad de heroísmo individual está presente, de forma más o menos directa, en gran parte de las tramas: Jensen en 13RW, Jones en JJ, Osborne en THT, Abernathy en WW. Todos estos personajes optan, en un momento u otro, por esa tendencia al heroísmo salvador inherente a la ficción estadounidense (Aguado Peláez, Cuando el miedo), aunque la mayoría terminan acudiendo a su grupo buscando en las redes el apoyo necesario para intentar cambiar -o eliminar- las lógicas de la matriz de dominación.

\section{CONCLUSIONES: LOS SILENCIOS TRAS LA MATRIZ}

Hasta aquí, hemos realizado un análisis a través de la matriz de dominación de Collins para analizar unos textos culturales producidos durante la década de los '10 en los EE.UU. Es decir, estas narraciones están insertas en una democracia representativa fuertemente vinculada al capitalismo que, a nivel formal, mantiene un compromiso explícito con la diversidad, la igualdad y las libertades. Sin embargo, a nivel experimental, este sistema abraza múltiples lógicas de opresión superpuestas como son el clasismo, el sexismo o el racismo, entre muchas otras, que impregnan la matriz de dominación desde el nivel estructural al interpersonal.

Aunque no sin resistencias. Así, en la última década, los EE.UU. han sido testigos de la implosión de diferentes movimientos sociales dirigidos a contestar de abajo arriba esas lógicas insertas en la matriz. Es decir, cuestionar el clasismo -Occupy Wall Street (OWS, 2011)-, el sexismo -Me Too (2017) - y el racismo -Black Lives Matter (BLM, 2013)-. Estos movimientos surgidos a nivel interpersonal -en las redes comunitarias- no tardan en subir un escalón de la matriz e impactar en el cultural.

Pues, como explica Collins, el dominio cultural es un campo que puede usarse para defenderse de las ideas hegemónicas de la cultura dominante pero también para crear un conocimiento contra-hegemónico que fomente las resistencias (Black Feminist 285). Así, en la última década, 
la acción de las calles se traslada al terreno de lo simbólico del campo mediático y las tramas comienzan a abandonar la normatividad dominante hasta el momento. Es decir, la pequeña pantalla se abre a personajes femeninos y otros colectivos alternos -LGTBI, racializados- y, con ellos, a la inclusión de diferentes voces, experiencias y temáticas otrora olvidadas (Aguado-Peláez).

En esta línea, las cinco series aquí analizadas -que estrenan entre 2015 y 2017 y cuyas tramas continúan hasta el momento de redactar el presente artículo- cuentan con mujeres y otros colectivos alternos tanto delante como detrás de las cámaras, en sus obras originales y/o en sus adaptaciones. Y, con ello, se pone el foco en la importancia de la inclusión de voces heterogéneas capaces de narrar experiencias diferentes desde cuerpos diferentes. Un principio de resistencia que parte de la propia consciencia de opresión en un contexto marcado por la ascensión conservadora de Donald Trump y la potencia de los movimientos feministas -como se puede ver en el \#MeToo o la Marcha de las Mujeres-, entre otros. Algo que también impacta en la forma de abordar la representación de las violaciones.

En este sentido, la interseccionalidad y la matriz de Collins permiten comprobar que las narraciones analizadas apuestan por dibujar la violencia sexual como un problema estructural. De este modo, el agresor ya no es un monstruo dibujado a golpe de estereotipo sino que es un ciudadano exitoso que se construye desde la normatividad. Es un hombre blanco, heterosexual, de clase alta que no se ampara en la locura o el sadismo para violar sino en una posición de poder derivada de una matriz que legitima sus lógicas. El propio sistema es un cómplice silencioso del violador.

Y esto lo sabemos porque estas ficciones son relatadas a través de los ojos de las supervivientes. Sus voces están legitimadas en primera línea de la narración, permitiendo al espectador atender al dolor y al trauma derivados de la agresión, al desamparo y los recelos producidos por la falta de apoyo social, al despertar y la resistencia en red posterior. En definitiva, a escuchar sus historias y empatizar con ellas.

Sin embargo, es significativo que en todas estas series las voces legitimadas para relatar esas vivencias estén ampliamente amparadas por la normatividad. Es decir, la credibilidad sigue en manos de esa víctima 
ideal dibujada a través de ejes de privilegio. Y, fuera de plano, quedan las vivencias de los cuerpos con discapacidades, racializados, trans... En esta línea, las cinco narraciones parecen recoger ciertos vicios presentes en el feminismo hegemónico y que han marcado movimientos como el Me Too. Al fin y al cabo, no hay que olvidar que \#MeToo fue un término acuñado por Tarana Burke, una activista afroamericana por los derechos civiles del Bronx, para denunciar la doble victimización que sufren las supervivientes de violencia sexual que terminó siendo monopolizado por el feminismo blanco, dejando en un segundo plano las voces y vivencias de las compañeras racializadas (Onwuachi-Willig).

Por ello, para que la representación de las vivencias de las mujeres que sufren violencia sexual supere las lógicas de dominación presentes, sería necesaria una mayor diversidad en las tramas que recogiera las experiencias y los dolores encarnados en cuerpos diferentes desde voces diferentes. Para que, en ese juego de complicidad en el que público y la protagonista intiman, puedan empatizar con perfiles más allá de la normatividad. Y, para ello, seguramente tengamos que volver a mirar la necesidad de incluir a un lado y al otro de la pantalla, en texto y producción, a personas subalternas que puedan incorporar sus resistencias y trabajar en el cambio hacia una mayor profundidad democrática.

\section{BIBLIOGRAFÍA}

Aguado-Peláez, Delicia. Cuando el miedo invade la ficción. Análisis de Perdidos (Lost, ABC, 2004-2010) y de otros Quality Dramas de la era Post. Leioa: Universidad del País Vasco, 2016. <https://addi.ehu.es/handle/10810/17613>

—. «(De)construyendo reinas desde la vulnerabilidad: Violencia simbólica en Juego de Tronos»». La desigualdad de género invisibilizada en la comunicación. Eds. Juan Carlos Suárez Villegas, Luis Alfonso Guadarrama Rico, Janett Valero Vilchis y Paola Panarese. Madrid: Dynkinson, 2017.

-. «Feminicidios con perspectiva de género. Un análisis interseccional de The Fall (La Caza)». Investigaciones Feministas 8 (2017): 186-201. <http://revistas. ucm.es/index.php/INFE/article/view/54868>

- Jessica Jones: El viaje de la (anti)heroína contra la violencia machista». Superhéroes y vigilantes: las ideologías tras la máscara. Ed. Alfonso Rodríguez de Austria. Sevilla: Doble J, 2017. 145-168. 
Violaciones en serie: dominaciones y resistencias tras las agresiones sexuales de ficción en la era del \#MeToo

Bonino, Luis. "Masculinidad hegemónica e identidad masculina». Dossiers Feministes 6 (2002): 7-35.

Bourdieu, Pierre. Sobre la televisión. Barcelona: Anagrama, 1996.

—. La dominación masculina. Barcelona, Editorial Anagrama, 2000.

Brey, Iris: Sexo y Series. Las sexualidades femeninas, una revolución televisiva. Sevilla: Héroes de Papel, 2018.

Collins, Patricia Hill. Black Feminist Thought. Knowledge, Consciousness, and the Politics of Empowerment. New York: Routledge, 2000.

—. «The difference that power makes». Investigaciones feministas 8 (2017): 19-40. Crenshaw, Kimberlé. «Mapping the margins: Intersectionality, Identity Politics, and Violence against Women of Color». Stanford Law Review 43.6 (1991): 1241-1299.

Davis, Angela. Mujeres, raza y clase. Madrid: Akal, 2018.

Despentes, Virginie. Teoría King Kong. Barcelona: Random House, 2018.

Foucault, Michel. Microfísica del poder. Madrid: Ediciones de la Piqueta, 1980.

Gay, Roxane. No es para Tanto. Notas sobre la cultura de la violación. Madrid: Capitán Swing, 2018.

Hall, Stuart. «Codificación y descodificación en el discurso televisivo». CIS 9 (2004): 210-236.

Hercovich, Inés. El enigma sexual de la violación. Buenos Aires: Biblos, 1997.

Ibarra, Pedro e Idoyaga, Petxo. «Racionalidad democrática, trasmisión ideológica y medios de comunicación». Zer 5, (1998): 157-181.

Igartua, Juan José. «Identificación con los personajes y persuasión incidental a través de la ficción cinematográfica». Escritos de psicología 2.1 (2008): 42-53.

Juliano, Dolores. Tomar la palabra. Mujeres, discursos y silencios. Barcelona: Bellaterra, 2017.

Martín-Barbero, Jesús. De los medios a las mediaciones. Comunicación, cultura y hegemonía. Barcelona: Anthropos, 2010.

Mattelart, Armand y Neveu, Erik. Introducción a los estudios culturales. Barcelona: Paidós Ibérica, 2004.

Mulvey, Laura. «El placer visual y el cine narrativo». Crítica feminista en la teoría e historia del arte. Comps. Karen Cordero e Inda Sáenz. México: Universidad Iberoamericana, 2007. 81-93.

Onwuachi-Willig, Angela. "What About \#UsToo: The Invisibility of Race in the \#MeToo Movement». The Yale Law Journal Forum 128 (2018): 105-120.

Pateman, Carole. El Contrato Sexual. Barcelona: Anthropos, 1995. 
Violaciones en serie: dominaciones y resistencias tras las agresiones sexuales de ficción en la era del \#MeToo

Piñuel, José Luis. «Epistemología, metodología y técnicas del análisis de contenido». Estudios de sociolingüística 3.1 (2002): 1-42.

Platero, Raquel Lucas. Intersecciones: cuerpos y sexualidades en la encrucijada. Barcelona: Ediciones Bellaterra, 2012.

Puleo, Alicia. «El patriarcado ¿una organización superada?», Temas para el debate 133 (2005): 39-42.

Ruiz Olabuénaga, José Ignacio. Metodología de la investigación cualitativa. Bilbao: Universidad de Deusto, 2012.

Segato, Rita Laura. Las estructuras elementales de la violencia: ensayos sobre género entre la antropología, el psicoanálisis y los derechos humanos. Buenos Aires: Prometeo Libros, 2010.

Young, Iris Marion. La justicia y la política de la diferencia. Madrid: Cátedra, 2000. 